\title{
Determinants of Social Media Adoption by Large Companies
}

\author{
Felipe Bogea ${ }^{1^{*}}$ Eliane Pereira Zamith Brito ${ }^{1}$
}

\begin{abstract}
Social media marketing has become a central issue for companies and marketers. Few studies have, however, specifically researched factors and barriers influencing the adoption of social media at company level. This study addresses this gap by focusing on furthering the theory involved in the adoption social media at company level. Based on the findings of semi-structured in-depth interviews with 17 marketing executives of large companies in Brazil, six variables that weigh in the adoption of social media were identified: the demonstrability of the results, the customers' presence on Social media, knowledge of social media, stakeholder influence, common sense as related to digital marketing and the executive's age. Additionally, we propose a theoretical model of social media adoption, in the light of the Technology Acceptance Model (TAM).
\end{abstract}

Keywords: social media adoption; social media marketing; technology adoption; TAM

Submitted: April $4^{\text {th }}, 2017$ / Approved: April 25 th 2018

\section{Introduction}

Social media is a general term employed to describe several webbased platforms developed for individuals and communities to share information and opinions and to co-create content (Kietzmann, Hermkens, McCarthy, \& Silvestre, 2011). The mass adoption of social media by individuals has increased consumer power which, in its turn, has pressured companies into adopting and managing social media communication (Sinclaire \& Vogus, 2011). Its increasing relevance has influenced companies to allocate more investment to create or promote companies' brands and content rapidly through social media marketing efforts. Thus, social media has become a central issue for companies and marketers (Kumar, Vikram, Mirchandani, \& Shah, 2013).

For Dahnil, Marzuki, Langgat, \& Fabeil (2014), the increasing trend towards the use of social media by companies offers a clear research opportunity. For those authors, it is fundamental to understand the factors that encourage the adoption of social media marketing among companies. For Kuikka and Akkinen (2011), there is a vast literature on the barriers faced at company level by organizations adopting a new enterprise system but there are very few studies that have undertaken research specifically into the adoption and use of social media. Moreover, before practical guidelines to support managers can be defined, the overall phenomenon of the adoption of social media requires more research and calls for more empirical evidence (Jobs \& Gilfoil, 2014).

On a broader perspective, the implementation of new internet-based technologies has been identified as a relevant process for moving a company toward electronic business. In this sense, business attitudes regarding the adoption of internet-related innovation have been acknowledged as a critical factor for executing e-business strategy. There is limited research on the adoption of business-level technology as compared to research examining the adoption of individual-level technology (Yu \& Tao, 2009).
The present research will draw on the TAM proposed by Davis (1989) to understand company level adoption of social media. Since its conception in 1989, TAM has become accepted as a solid and parsimonious model for predicting user adoption in a variety of contexts (Venkatesh \& Davis, 2000). Although TAM is a robust model, increasing knowledge of the determinants of perceived usefulness (PU) and perceived ease of use (PEOU) it would allow practitioners and academics to better design and implement managerial actions that would increase the user's adoption of new systems (Venkatesh \& Davis, 2000; Yu \& Tao, 2009).

The aim of this research is to further the theory of social media adoption at company level and the theory underlying the adoption of new technologies. The research question is: what are the factors and their influence on the adoption of social media by large for-profit companies?

This research contributes to theory in two ways: (i) it furthers knowledge of the factors influencing the adoption of social media, and (ii) it develops a theoretical model to explain the adoption of social media, within the perspective of TAM.

Within a managerial perspective, this research is relevant for social media technology providers, for marketing agencies and for marketing executives. For the technology providers, it can show what barriers and concerns they may need to tackle to increase the adoption of their platforms. For the agencies and marketing executives, it contributes to an understanding of the factors that influence adoption and employment of new marketing tools, which can lead to better decisions for social media marketing.

This study is structured in five sections. The first section introduces the theme and describes its importance. In the second, there is a theoretical review of the adoption of social media at company level, and of TAM. The third section describes the methodology employed. In the fourth and fifth sections, the results are presented and discussed.

(1) Marketing, Fundação Getúlio Vargas (FGV/EAESP), R. Itapeva, 474 - Bela Vista, São Paulo, Brazil. Corresponding author: fbogea@gmail.com 


\section{Theoretical Background}

\section{Social Media Adoption}

Research into the adoption of social media by companies is a recent research subject on which there are few studies. The existing literature has studied different aspects of social media adoption. It is possible to identify three main topics researched: (i) the level of adoption of social media by a certain group of organizations; (ii) the factors and barriers influencing adoption; (iii) the adoption process at company level - stages of adoption. This study and literature review will focus on the factors involved in such adoption and the barriers which hinder it.

Dahnil et al. (2014) identified five groups of internal and external factors that could affect the adoption of social media marketing. The first group of factors is related to the end users themselves: training and knowledge of the social media environment and perceived usefulness. The second group is related to organizational resources: whether top management has allocated resources in terms of money, time and personnel, to social media marketing. The third is related to the technological limitations of the platforms. For example, the difficulty involved in the measurement of business results. The fourth factor group is related to the company's leader's attitude towards social media. Lastly is the business environment. In this group, competitors' behavior may exercise some influence as well also as a country's infrastructure, as in the case of internet broadband distribution.

Kuikka and Akkinen (2011) have divided social media adoption barriers into two broad categories: internal challenges, involving the management challenges within the company, and external challenges, which are normally associated with company image, brand or external relations. The authors identified five categories of internal challenges: resource limitations, unclear corporate ownership/responsibility for social media, authority over social media content, negative attitudes towards social media and economic challenges (costs $\mathrm{x}$ benefits of social media). The authors also identified three external challenge categories: company's reputation management, potential legal issues and public versus private use of social media. Kuikka \& Akkinen (2011) acknowledge that the frontiers between these categories are not clearly defined and that some overlaps exist between them.

For Sinclaire \& Vogus (2011), studying fast growing American companies, the main factor for companies' adoption of social media was the mass adoption of social media by consumers. Other factors also considered by companies' executives were: ease of implementation and increased ability to communicate with customers.

Michaelidou, Siamagka, and Christodoulides (2011) researched the adoption of social media in the context of SMEs companies in the B2B space. The author identified five key barriers: lack of relevance of SNS within the industry the company operates (a major challenge in this study, but which may be highly specific to B2B companies), uncertainty of benefits resulting from using SNS, the personnel's unfamiliarity with and lack of technical skills, the great investment necessary in terms of time, and competitors' not using SNS.
In the only study conducted in Latin America (Brazil), Serra, Storopoli, Pinto, and Serra (2013) discovered that companies' adoption of social media is facilitated by its ease of access and the possibility of using it advantageously in selling and as a client relationship channel. On the other hand, the barriers were lack of qualified work force, lack of specific knowledge of social media and the challenge of attracting customers to interact with the company through the social media channel.

Wamba and Carter (2014) researched both organizational and individual factors that could drive social media adoption by SMEs. Their results indicated that manager's age, size of firm, innovativeness, and industrial sector had a positive relation to adoption.

In brief, the existing literature presents various points of view as regards adoption factors and the supporting theories employed to explain the adoption of social media.

\section{Technology Adoption Theories}

There are three distinct approaches to research into the adoption of innovations: the individualist, structuralist, and interactive processes (Kautz \& Nielsen, 2004). The individualist and structuralist approaches take individual actors and organizations as their units of research. As regards the first two approaches, past research has focused mainly on variables related to the individual or to organizations, such as individual characteristics and size of organization (Sarosa, 2012). The present research will also adopt an individualist and structuralist approach.

In order to investigate social media adoption by large companies, the present research focuses on TAM. Our academic approach, following Siamagka et al. (2015), aims to adopt a theoretical framework in which constructs are more responsive to empirical operationalization (e.g. TAM) than is the case with alternative theories such as that of Rogers (1995).

In order to investigate social media adoption by large companies, the present research focuses on TAM. Our academic approach, following Siamagka et al. (2015), aims to adopt a theoretical framework in which constructs are more responsive to empirical operationalization (e.g. TAM) than is the case with alternative theories such as that of Rogers (1995).

TAM was proposed by Davis in 1986 (Davis, 1989) to explain and predict users' adoption/acceptance or rejection of new technologies. TAM is conceptually based on the Theory of Reasoned Action (TRA) (Ajzen \& Fishbein, 1980) which postulates two behavioral beliefs, perceived usefulness (PU) and perceived ease of use (PEOU), as fundamental determinants of attitude towards behavioral intentions and actual usage behavior (AB). Perceived usefulness is defined as "the degree to which a person believes that using a particular system would enhance his or her job performance". Perceived ease of use is defined as "the degree to which a person believes that using a particular system would be free of effort" (Davis, 1989). 
In TAM, behavioral intention to use leads to actual IT usage behavior. TAM proposes that the personal attitudes towards the technology influence the adoption and use of that technology. Therefore, TAM's belief-attitude-intention-behavior connection predicts user acceptance of new technologies (Lederer, Maupin, Sena, \& Zhuang, 2000).

Because of its universal applicability and due mostly to its parsimony, TAM has become the most popular model and has been globally used in a diverse set of technology adoption studies (Al-Ghaith, 2015) the Technology Acceptance Model (TAM. However, when compared to the extensive individual-level TAM literature, business-level research that uses TAM is relatively rare. Having said which, there are few organizational-level technology adoption studies (Siamagka et al., 2015; Zain, Rose, Abdullah, \& Masrom, 2005)the Technology Acceptance Model (TAM. For Yu and Tao (2009) there is still a gap in the knowledge and understanding of the adoption of technology at company level.

Different research using TAM has evidenced that perceived usefulness has constantly been a strong predictor of usage intention.
Thus, considering the importance of this construct, a better understanding of its determinant factors would allow the development of organizational interventions that would enhance user adoption of new systems (Venkatesh \& Davis, 2000).

For Lee, Kozar and Larsen (2003) even though TAM has been a robust model, it is relevant to incorporate more variables and to explore boundary conditions. For those authors, a greater understanding of factors contributing to ease of use and usefulness is needed. A specific area at present under study is examining different information systems and environments.

Different researchers have used TAM to study companies' web-related adoption of technologies such as e-mail and word processing (Lederer et al., 2000). Siamagka et al. (2015) have used TAM to explain companies' adoption of social media. The authors identified factors that determine adoption and their results indicate that PU of social media, within B2B companies, is determined by image, perceived ease of use and perceived barriers (Figure 1). Furthermore, they found evidence that organizational innovativeness and PU significantly affect the adoption of social media.

Figure 1: Social Media Adoption Model

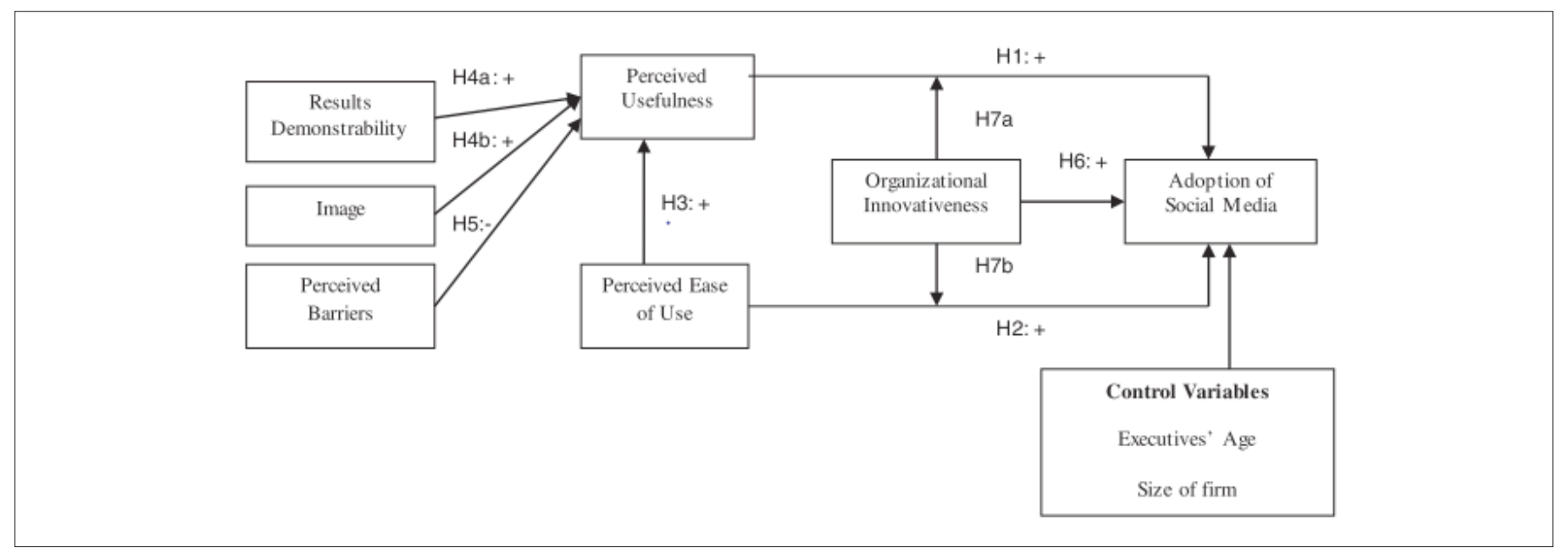

Source: Siamagka et al., (2015)

\section{Methodology}

This study is qualitative and exploratory in nature and seeks to create a new and enhanced understanding of an emerging and complex phenomenon (i.e. the adoption of social media by companies). This research has adopted a realist approach.

The data presented comes from the participants' experience in adopting social media networks for their businesses. The method chosen for collecting these data is the semi-structured interview (Creswell $\&$ Creswell, 2017). The qualitative approach with one-to-one semistructured interviews permits the exploration in depth of all the facets and perceptions of marketing executives within the social media adoption process (Nah \& Saxton, 2012)capacity, governance and en- vironment. Using Twitter, Facebook, and other data on 100 large US nonprofit organizations, the model is employed to examine the determinants of three key facets of social media utilization: (1.

The interviewees were not selected randomly. They were chosen deliberately since they were in a position to provide relevant insights into the understanding of the use and adoption of social media. The executives had an intermediate or senior managerial position within the marketing function (or in overseeing marketing, for instance, a Vice President of sales and marketing) and worked for large corporations.

The starting point for gathering research participants came from the researchers' professional network and, as it is a conceptually driven sampling, new informants were included as information 
called for exploration from a different perspective, so new managers were invited to take part in the research. The research development process has a constant reciprocal flow between data collection and analysis, leading to concepts and back to data collection in a permanent cycle that only ends when there is saturation (Corbin \& Anselm, 2014).

A total of seventeen marketing executives from different industries were interviewed during 2015 and 2016. The interviews took place in the interviewee's company's office (except for one that was undertaken by Skype call) and lasted, on average, 47 minutes. The interview guide was composed of questions based on: (i) existing literature on the adoption of social media and organizational decisions for the adoption of innovative technologies, and (ii) the field experience of the authors. Each interview was audiotaped and recorded with the explicit permission of the interviewee. Interviews were transcribed verbatim, and the software Atlas.TI, version 7.5 for qualitative analysis, was used to perform the analysis. Data were hand-coded paragraphby-paragraph.

The data set was analyzed using thematic analysis. Thematic analysis includes the identification in a data set - be that a number of interviews or focus groups, or a range of texts - of repeated patterns of meaning (Braun \& Clarke, 2006). The development of themes and codes was undertaken using a "theoretical" thematic analysis approach. According to Braun and Clarke (2006), this approach is directed by the researcher's theoretical or analytical interest in the topic and is, therefore, more explicitly analyst-driven.

With this approach, the codes were initially developed based on the existing literature and researcher's own field experience. As the research progressed, transcripts were read several times to identify the key themes and categories. This constant revision led to both mapping of recurring patterns of social media adoption and also of new codes.

From the content analysis, different factors and relations emerged. These factors were confronted with the existing literature on social media adoption and of TAM. These comparisons made it possible to identify factors and relations that had not previously been considered in the literature and to corroborate some factors and relations already identified, thus expanding knowledge of the phenomenon.

The two researchers, who reviewed the transcripts independently, established inter-coder reliability. Divergencies in the coding were resolved by discussion.

\section{Results}

A theoretical model for social media adoption was proposed (Figure

2) based on the literature and the field research results. The research model should not be over-complex, allowing a solid research base for future firm-level TAM studies, but at the same time should not be overly simple in its scope avoiding critical reviews of TAM-related studies (Bagozzi, 2007; Yu \& Tao, 2009).
Figure 2: Proposed model of social media adoption

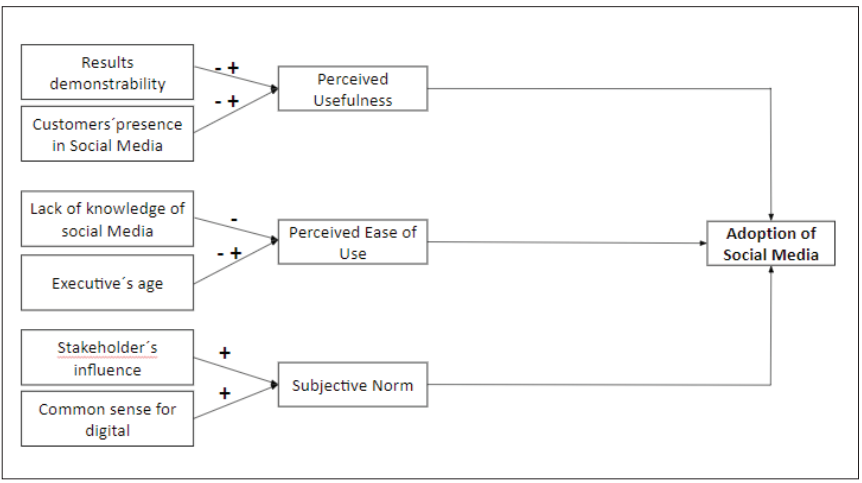

Source: the authors

The most common point present in all the interviews is related to social media results, which was defined as "Results Demonstrability" in the proposed model. According to Venkatesh and Davis (2000), results demonstrability is related to the extent to which the results of using a certain technology are visible within a company and also relates to the challenges employees face in communicating the results to other corporate stakeholders. For these present authors, systems may not be adopted despite being effective, if users have difficulty in relating job performance to the adoption of the system.

TAM proposes that results demonstrability has a positive influence on perceived usefulness. Thus, it is to be expected that users should have a better PU if the relation between system usage and positive results are clearly visible (Venkatesh \& Davis, 2000).

For a certain group of the interviewees, there is great uncertainty about return on investment and there are challenges associated with demonstrating the results obtained in social media marketing. This is in line with Jobs \& Gilfoil (2014), for whom lack of financial return is the main reason companies make but little investment in social media. From the executives' point of view:

"We pay to advertise, to get more clicks and likes. But at the end of the day, I am always left with that doubt: how much will those likes revert to sales?" Beauty and cosmetics industry executive

"I am making a great effort for us to use all the social media performance tools focused on CRM, in client acquisition, but so far we have performed poorly in all the tests." Retail industry Executive

"I think that commercially [social media] has not proven itself. There are a lot of cool things in digital communication, but when you look at the financial results of the big ecommerce players, you see a negative [cash flow]" Retail industry Executive

This is probably due to the facts that social media channels are very recent and that they are more, for most industries, a relationship channel than a direct sales channel. For Weinberg, Pehlivan, \& Street (2011) management has a strong need for "proof" of return on marketing investment (ROI) and an apparent uncertainty about the return on social media. On the other hand, there is a group of executives that strongly believe 
in social media results and the ease of demonstrating results. From their point of view:

"What I find very interesting in the online world is that everything is measurable. The banners that we bought, the media we purchased, all the adds that we bought in Adwords, everything that was done on Facebook, which posts were more engaging... At the most [regarding TV] you would raise questions as to why to invest or not to invest in a certain TV show. But you cannot measure the return in the way that you measure the online." Retail industry Executive

"Int: do you believe that social media marketing produces results for your business?

Exec. Certainly! Many!

Int: How do you see these results?

Exec: When you post something and people are discussing it, you get to know who the person who is buying and is eager to know and buy more is. So it is much quicker to measure things using social media than any other form of stakeholders' communication." Finance industry Executive

So considering the two groups found we propose that results demonstrability have a direct impact, positive or negative, on social media PU.

The presence - or otherwise - of a company's customers on social media platforms was a factor frequently mentioned in the interviews. Sometimes it was mentioned as a determining factor in investment and at others it was mentioned as a barrier to investment. From the interviews:

"Every year we are increasing a bit [social media investment]. And this is related to the fact that our target audience in several products, especially on fiber broadband, is daily more present in the digital world than in the offline/TV world" Telecom industry Executive

"Product A or even Product B can be a product for younger people and can be a category that needs a larger investment in social media. If I want to talk to a younger generation, they are more present in the social media." Food industry Executive

These points of view lead to the following proposition: the degree of the customer's presence on the social media has an impact on the perceived usefulness of the social media.

These points of view lead to the following proposition: the degree of the customer's presence on the social media has an impact on the perceived usefulness of the social media.

The knowledge of the social media was also a preeminent topic in the interviews. This is consistent with previous literature that identified managerial knowledge as a key factor in adopting new technologies. Aguila-Obra \& Padilla-Meléndez (2006) identified mana- gerial capabilities, together with technological resources, as the main organizational factors that explain Companies' adoption of internet technology tools. Kiron, Palmer, Phillips, \& Kruschwitz (2012) found evidence that the main barrier to adoption of social media is a lack of management understanding and knowledge of social media marketing. For Kietzmann et al. (2011), despite social media's importance, many executives eschew or ignore this form of media because they don't understand what it is, the various forms it can take, or how to engage with it and learn. Serra et al. (2013) and Kuikka and Akkinen (2011) also identified this barrier.

Additionally, it seemed that younger executives more accustomed to social media were more inclined to invest in and deploy social media. This is probably related to a better understanding and knowledge of it.

"Exec: I think they [the board] still don't understand [social media] ... they are at that level where talking about digital marketing means to have a website with all the company's information.

Inter: And this lack of knowledge could influence investments levels?

Exec: I think so... I think that because when you speak at board level, within this decision-making process of investment allocation, they have an active role." Food industry Executive

"This online world... I am 42 years old and I have the impression that I am super old and outdated". Telecom industry Executive

"On my part, there is a large gap in the understanding of social media. I feel that I don't fully understand its metrics and that it is always changing". Beauty and cosmetics industry executive

Thus, this leads to two propositions: (i) the lack of knowledge of social media impacts the perceived ease of use of social media negatively; (ii) the executive's age can affect the adoption of social media.

Furthermore, an interesting relation between lack of knowledge and the influence of marketing agencies emerged from the interviews. It seems that executives readily acknowledge their lack of knowledge (for themselves and their teams) and rely heavily on external advice from specialists. This finding is corroborated by other studies that have recognized the influence of external expert advice on the companies' adoption process (Aguila-Obra \& Padilla-Meléndez, 2006).

"So, social media was something new to me. It was Agency X which gave me confidence as to how to make investments and how to act on Facebook and other media as well. Practically the strategy came from the agency ready for us to approve." Retail industry Executive

"I say that we are still learning [social media marketing]. I don't think that I know anything; I still need to learn a lot to be able to use this tool correctly and assertively. We are still greatly influenced by those who understand it. For instance, the agency that works with us." FMGC industry Executive 
Besides the specialists, other stakeholders appeared to exercise influence on the decision-making process. They are mainly represented by the younger people in the executive's team. For instance:

"I have X [a mid-level analyst] on my team. He is an expert, a guru. He is the one who really defines the digital strategy." Finance industry Executive

Some executives argue that they believe in the channel, but other stakeholders in the company are not aligned with this vision.

"When we present a campaign in digital marketing normally the board says that it is just a complement. An investment in social media will not generate a quick sales result. It will not generate consumption in the retail chain the next morning. We still have this vision at board level". Food industry executive

Int: "So what prevents you from doubling your investment level in social media?"

Exec: "It is the short-term view. Truly. For you to invest in social media, in building your brand, your perspective has to be longerterm than the quarter. At the end of the day, it boils down to your CEO's agenda." Telecom industry Executive

Previous research has evidenced that organizational decision-making behavior is not only influenced by the rational and irrational components of individual decisions, but is also influenced by the multidimensional stakeholders (Nelson \& Quick, 2006). Yu \& Tao (2009) also corroborate the influence of the Social Norms as a strong influencer of the adoption of business-level technology.

Considering the literature and the evidence provided by the interviews, we propose that: Stakeholders' influence has a positive impact on the Subjective Norm.

In the interviews, a common point of view that digital and social media marketing are the future way ahead was frequently mentioned. Interviewees, to different degrees, seemed confident that there is no going back on investing in digital marketing and that their industry or the market as a whole was moving in that direction. From the interviewees' point of view:

"Everybody is saying that digital media is growing, that it is very important, that it is growing and that it is a much more direct means of conversation with consumers" FMGC industry executive

"Why is it [investment in social media marketing] not zero? There is common agreement that zero investment is wrong because the world is changing in this direction. It is, therefore, something we should invest in." Telecom industry executive

"Because we so often hear that this [social media marketing] is the way ahead and by seeing the example of big companies... we end up saying 'ok'." FMGC industry executive.
In view of the literature and the evidence presented in the interviews, we propose that: a Common sense for digital media influences the Subjective Norm positively.

\section{Conclusions}

There is limited research on the adoption of social media at the company level. In this sense, this research contributes to existing theory by building on previous work on models of the adoption of social media. The proposed model of adoption corroborates some of the findings of Siamagka et al. (2015) and, at the same time, proposes that other variables also influence adoption. Specifically, we identified a variable (common sense for digital) that has not been acknowledged previously in the literature.

From a managerial point of view, this research is relevant for large companies' executives, social media platforms, and agencies as it presents perspectives and insights on levers favorable to social media and barriers to it that marketing executives have. Each stakeholder may use this information to minimize barriers to adoption and to foster levers. For instance, the training and presentation of success stories may be very useful for executives that shy away from social media marketing.

There are limitations to this study. First of all, our results are based on a small sample of interviews, thus they cannot be extrapolated to apply to all companies in the process of adopting and using social media. The interviewees were also handpicked from the researcher's professional network and may thus be biased.

This research can be extended with a quantitative phase to further explore the propositions and relations identified. Other potentially interesting research topics include the evaluation of barriers to adoption in another group of organizations such as the SME business.

\section{References}

Aguila-Obra, A. R. Del, \& Padilla-Meléndez, A. (2006). Organizational factors affecting Internet technology adoption. Internet Research, 16(1), 94-110. doi:10.1108/10662240610642569

Ajzen, I., \& Fishbein, M. (1980). Understanding Attitudes and Predicting Social Behavior. Englewood Cliffs, NJ: Prentice-Hall.

Al-Ghaith, W. (2015). Applying the Technology Acceptance Model to Understand Social Networking Sites (SNS) Usage: Impact of Perceived Social Capital. International Journal of Computer Science and Information Technology, 7(4), 105-117. doi:10.5121/ijcsit.2015.7409

Andzulis, J. “Mick," Panagopoulos, N. G., \& Rapp, A. (2012). A Review of Social Media and Implications for the Sales Process. Journal of Personal Selling and Sales Management, 32(3), 305-316. doi:10.2753/ PSS0885-3134320302 
Bagozzi, R. P. (2007). The Legacy of the Technology Acceptance Model and a Proposal for a Paradigm Shift. Journal of the Association for Information Systems, 8(4), 244-254. doi:10.17705/1jais.00122

Braun, V., \& Clarke, V. (2006). Using thematic analysis in psychology. Qualitative Research in Psychology, 3(2), 77-101. doi:10.1191/1478088706qp063oa

Corbin, J., \& Anselm, S. (2014). Basics of qualitative research. Sage Publications.

Creswell, J. W., \& Creswell, J. D. (2017). Research design: qualitative, quantitative, and mixed methods approaches. Sage Publications.

Dahnil, M. I., Marzuki, K. M., Langgat, J., \& Fabeil, N. F. (2014). Factors Influencing SMEs Adoption of Social Media Marketing. Procedia - Social and Behavioral Sciences, 148, 119-126. doi:10.1016/j.sbspro.2014.07.025

Davis, F. D. (1989). Perceived Ease of Use, and User Acceptance of Information Technology. MIS Quarterly, 13(3), 319-340. doi:10.2307/249008

Jobs, C. G., \& Gilfoil, D. M. (2014). A Social Media Advertising Adoption Model for Reallocation of Traditional Advertising Budgets. Academy of Marketing Studies Journal, 18(1), 235-249. Retrieved from https://search.proquest.com/openview/3060c8d7a791c68ac3e402a74 309302a $/ 1$ ?pq-origsite $=$ gscholar $\&$ cbl $=38744$

Kautz, K., \& Nielsen, P. A. (2004). Understanding the implementation of software process improvement innovations in software organizations. Information Systems Journal, 14(1), 3-22. doi:10.1111/j.13652575.2004.00156.x

Kietzmann, J. H., Hermkens, K., McCarthy, I. P., \& Silvestre, B. S. (2011). Social media? Get serious! Understanding the functional building blocks of social media. Business Horizons, 54(3), 241-251. doi:10.1016/j.bushor.2011.01.005

Kiron, B. D., Palmer, D., Phillips, A. N., \& Kruschwitz, N. (2012). Social Business: What Are Companies Really Doing? MIT Sloan Management Review, 31. Retrieved from https://sloanreview.mit.edu/ projects/social-business-what-are-companies-really-doing/

Kuikka, M., \& Akkinen, M. (2011). Determining the Challenges of Organizational Social Media. In European Conference on Information Systems (ECIS). Retrieved from http://aisel.aisnet.org/ecis2011

Kumar, V., Vikram, B., Mirchandani, R., \& Shah, M. (2013). Creating a Measurable Social Intangibles and Tangibles for Hokey Pokey Creating a Measurable Social Media Marketing Strategy: Increasing the Value and ROI of Intangibles and Tangibles for Hokey Pokey. Marketing Science, 32(2), 194-212. doi:10.1287/mksc.1120.0768

Lederer, A. L., Maupin, D. J., Sena, M. P., \& Zhuang, Y. (2000). The technology acceptance model and the World Wide Web. Decision Support Systems, 29(3), 269-282. doi:10.1016/S0167-9236(00)00076-2
Lee, Y., Kozar, A. K., \& Larsen, K. R. T. (2003). The technology acceptance model: Past, present, and future. The Communications of the Association for Information Systems, 12(1), 752-780. Retrieved from http://aisel.aisnet.org/cais/vol12/iss1/50

Michaelidou, N., Siamagka, N. T., \& Christodoulides, G. (2011). Usage, barriers and measurement of social media marketing: An exploratory investigation of small and medium B2B brands. Industrial Marketing Management, 40(7), 1153-1159. doi:10.1016/j.indmarman.2011.09.009

Nah, S., \& Saxton, G. D. (2012). Modeling the adoption and use of social media by nonprofit organizations. New Media \& Society, $0(0)$, 1-20. doi:10.1177/1461444812452411

Nelson, D. L., \& Quick, J. C. (2006). Organizational Behavior: Foundations, Reality and Challenges. Nashville: Thomson.

Rogers, E. M. (1995). Diffusion of innovation (4th ed.). New York: Free Press.

Sarosa, S. (2012). Adoption of Social Media Networks by Indonesian SME: A Case Study. In International Conference on Small and Medium Enterprises Development (ICSMED 2012) (Vol. 4, pp. 244-254). doi:10.1016/S2212-5671(12)00339-5

Serra, B., Storopoli, J. E., Pinto, C. F., \& Serra, F. R. (2013). Mídias Sociais e Negócios: Um Estudo Delphi. Revista Ibero-Americana de Estratégia, 12(1), 236-253. doi:10.5585/riae.v12i1.1962

Siamagka, N. T., Christodoulides, G., Michaelidou, N., \& Valvi, A. (2015). Determinants of social media adoption by B2B organizations. Industrial Marketing Management, 51, 89-99. doi:10.1016/j.indmarman.2015.05.005

Sinclaire, J. K., \& Vogus, C. E. (2011). Adoption of social networking sites: An exploratory adaptive structuration perspective for global organizations. Information Technology and Management, 12(4), 293314. doi:10.1007/s10799-011-0086-5

Venkatesh, V., \& Davis, F. D. (2000). A Theoretical Extension of the Technology Acceptance Model: Four Longitudinal Field Studies. Management Science, 46(2), 186-204. doi:10.1287/mnsc.46.2.186.11926

Wamba, S. F., \& Carter, L. (2014). Social media tools adoption and use by SMEs: an empirical study. Journal of Organizational and End User Computing, 26(2), 1-16. doi:10.4018/978-1-4666-8614-4.ch035

Weinberg, B. D., Pehlivan, E., \& Street, F. (2011). Social spending: Managing the social media mix. Business Horizons, 54(3), 275-282. doi:10.1016/j.bushor.2011.01.008

Yu, C. S., \& Tao, Y. H. (2009). Understanding business-level innovation technology adoption. Technovation, 29(2), 92-109. doi:10.1016/j. technovation.2008.07.007

Zain, M., Rose, R. C., Abdullah, I., \& Masrom, M. (2005). The relationship between information technology acceptance and organizational agility in Malaysia. Information and Management, 42(6), 829-839. doi:10.1016/j.im.2004.09.001 
